Manuscript ID

ZUMJ-2105-2239

DOI

ORGINAL ARTICLE

10.21608/zumj.2021.77155.2239

\title{
Gall bladder Wall Thickness as Non-invasive Predictor of Oesophageal Varices in Cirrhotic Patients
}

\author{
Mohamed Abd Ellatif Afifi, M.D.; Mahmoud Rizk, M.D.; and \\ Ahmed Mohamed Hussein, M.D. \\ Internal Medicine Department, Hepatology and Gastroenterology Unit, Benha University, Egypt
}

Corresponding Author

Mohamed Abd Ellatif Afifi,

MD

Email:

dr_malatif82@yahoo.com

Gall bladder Wall Thickness

as Non-invasive Predictor of

Oesophageal Varices in

Patients with liver cirrhosis

$\begin{array}{ll}\text { Submit } & 2021-06-15 \\ \text { Date } & 21: 18: 20 \\ \text { Revise } & 2021-09-14 \\ \text { Date } & 14: 34: 42 \\ \text { Accept } & 2021-09-20 \\ \text { Date } & 11: 41: 04\end{array}$

ABSTRACT
Background: Upper gastrointestinal (GI) endoscopy is considered the gold standard in the diagnosis of oesophageal varices $\mathrm{OV}$ and the recommended investigation for screening all cirrhotic patients for the presence of $\mathrm{OV}$. Endoscopic screening of patients with liver cirrhosis adds a major burden to patients and also to endoscopic units. Non-invasive detection of OV helps to decrease the necessity of endoscopy as a screening method. Aim of the study: To assess the usage of the measurement of noninflammatory gall bladder wall thickness (GBWT) as a noninvasive predictor of the presence and size of OV and also to compare it with platelet count to splenic diameter. Patients and Methods: the current study was a cross-sectional study performed on 100 cirrhotic patients who attended the hepatology and gastroenterology unit of the Internal Medicine department, Benha University Hospital, Egypt. Abdominal ultrasound was done to measure GBWT, upper gastrointestinal (GI) endoscopy was done in detection of $\mathrm{OV}$, and blood tests were done. Patients were divided according to the presence of OV into two groups, Group I: included 50 cirrhotic patients with no OV (Non-OV group). Group II: included 50 cirrhotic patients with OV who were subdivided into two other subgroups, Group IIa: included 22 patients with small-sized O.V, and Group IIb: included 28 patients with large-sized O.V. Statistical analysis of the collected data was done. Results: GBWT was significantly higher in OV patients compared to the Non-OV group (mean: $4.2 \mathrm{~mm}$ vs. $2.7 \mathrm{~mm}, \mathrm{p}<0.001$ ), GBWT at cut-off $\geq$ $3.35 \mathrm{~mm}$, had a sensitivity and specificity of $68 \%$ and $78 \%$ respectively Conclusion: GBWT could be used as a non-invasive method in the prediction of OV.

Key words: Oesophageal varices, GBWT, Cirrhosis, Portal hypertension

\section{INTRODUCTION}

$\mathbf{L}$ iver diseases account for about two million deaths annually worldwide, half of them attributed to complications of liver cirrhosis (LC). According to the Global Burden of Disease 2010 study, cirrhosis is the eleventh most common cause of death globally and accounts for 1.6 percentage of the worldwide burden. [1]

LC is the most common complication of chronic hepatitis and is caused by increasing fibrosis. High portal pressure and/or hepatic impairment would be the effect of LC. Both of these, alone or in combination, can cause ascites, OV, hepatic encephalopathy (HE), hepatocellular carcinoma (HCC), hepatopulmonary syndrome, and coagulation issues, among other consequences. LC and its consequences not only have a negative impact on quality of life, but they are also linked to a high death rate. [2]

Portal hypertension is an inevitable sequel of LC that causes formation of portosystemic collateral veins, among them, OV have the greatest clinical impact because of their rupture resulting in fatal bleeding. Upper GI 
endoscopy is the gold standard in the diagnosis of $\mathrm{OV}$ and is recommended by all guidelines as a screening method in all patients with liver cirrhosis for $\mathrm{OV}$ at the time of diagnosis. Decompensated cirrhotic patients without OV need to be re-examined by repeat endoscopy annually and every two to three years in those with compensated disease [3].

A progression rate of $12 \%$ has been reported for development of $\mathrm{OV}$ in cirrhotic patients with clinically significant portal hypertension [4]. Despite the mortality of variceal hemorrhage has been decreased in the last decades, but still high with a six-week mortality reaches up to $37 \%$ [5] and a high recurrence rate following the first bleeding attack [6]. Despite this, it is considered an invasive diagnostic procedure with its carrying risks, and it is not always available in low resource countries with, in addition to the majority of cases underwent screening endoscopy either do not have varices or have varices which do not need prophylactic therapy [7]. Thus, the identification of nonendoscopic, non-invasive diagnostic methods that can precisely predict the presence of OV in patients with liver cirrhosis, particularly those with large size OV, can assist in the detection of patients at high risk and subsequently decrease the need for endoscopic screening [8].

Both the gall bladder and cystic duct venous drainage are directed into the hepatic circulation via tiny veins that ends in the portal venous system. As a result, portal hypertension may directly impact the gall bladder, creating a thickening of the gall bladder wall due to poor drainage [9].

The current study aimed to evaluate the diagnostic utility of noninflammatory GBWT as a non-invasive predictor of OV in cirrhotic patients as regard their presence and their size and to compare this with platelet count to splenic diameter ratio that is one of the most important noninvasive predictors of O.V.

\section{PATIENTS AND METHODS}

\section{Study design and settings}

This cross-sectional study was performed at the Hepatology and Gastroenterology unit of the Internal Medicine Department, Benha University Hospital, Egypt. During the period from Jan 2020 to June 2021.

\section{Study participants}

One hundred adult cirrhotic patients were involved in this study. All patients met the diagnostic criteria of LC by clinical, biochemical, and ultrasonographic data. Patients were divided according to the results of the upper GI endoscopy into two groups (Figure 1): Group I included 50 patients with LC with no endoscopic evidence of OV (NonOV). Group II included 50 patients with LC with OV, which was subdivided according to the size of OV into 2 subgroups: Group IIa included 22 patients with small OV $(<5 \mathrm{~mm})$. Group IIb included 28 patients with large OV (> 5mm).

\section{Inclusion criteria}

Patients of both sexes aged 18 years or more. Diagnosis of liver cirrhosis was based upon clinical, laboratory and ultrasonographic features.

\section{Exclusion criteria}

Patients who had a cholecystectomy, gall bladder stones, gall bladder polyps, or those with a history of recurrent upper abdominal pain. Patients who had endoscopic variceal ligation, sclerotherapy, or surgical intervention for OV. Patients with a history of previous or current use of beta-blockers, active or recent GI bleeding within 4 weeks, and finally, Patients complicated with HCC and those in whom endoscopy was contraindicated.

\section{Ethical clearance}

Informed consent was obtained from all subjects after taking the approval of the Institutional Review Board, Faculty of Medicine, Benha University. The work had been carried out in accordance with The Code of Ethics of the World Medical Association (Declaration of Helsinki) for experiments involving humans.

\section{Process}

Full history taking and thorough clinical examination for signs of LC and portal hypertension including ascites and splenomegaly. Biochemical parameters assessment, including platelet count for calculation of platelet count to spleen diameter ratio, serum albumin( $\mathrm{g} / \mathrm{dl}$ ), serum bilirubin(mg/dl), international normalization ratio(INR), and calculation of Child-Pugh 
classification.

Abdominal ultrasonographic examination was performed to evaluate the following parameters: Thickness of the gall bladder (measured twice following proper overnight fasting), splenic length (measured at a left lateral cross-section), portal vein (PV) diameter and presence or absence of ascites or HCC.

Upper GI endoscopy was performed using Olympus video endoscopy to detect the presence of $\mathrm{OV}$ and its grade, gastric varices, and portal hypertensive gastropathy (PHG). Ultrasound and endoscopic exams were conducted by senior specialists and experienced Gastroenterology trainees (> 3 years of experience).

\section{Statistical analysis}

Descriptive statistics for the variables were presented in the form of frequencies and percentages for categorical variables and in the form of mean, standard deviation, minimum, and maximum for numerical variables. Comparison of the characteristics of the patients who had OV and those who were free of OV was done by using (Chisquare test or Fisher exact test) for categorical variables, while these characteristics were compared by using the independent t-test for the numerical variables. Multiple logistic regression analysis test was used to analyze the association between the different variables and the presence of $\mathrm{OV}$ while controlling for the other variables. Sensitivity, specificity, PPV, and NPV were calculated for the cut-off points chosen based on the ROC. IBM SPSS version 26 for Windows software was used for the analysis. A (p-value) of $<0.05$ is considered significant.

\section{RESULTS}

Among the involved, one hundred of cirrhotic patients involved in the current study were classified into two groups; group I involved 50 cirrhotic patients without OV and Group II included 50 cirrhotic patients with OV, 59 patients were males while 41 were females, the mean age was $56.1 \pm 8$ years. Sixty-five patients were classified as Child A, while 21 patients were Child B and 14 patients were Child C. $71 \%$ of included patients did not have ascites. Mean portal vein and spleen diameters were $12.2 \pm 1.7 \mathrm{~mm}, 127.5 \pm 20.1$ $\mathrm{mm}$, respectively. Mean GBWT was high $(3.4 \pm 1.2 \mathrm{~mm})$, and the mean platelet count to spleen diameter ratio was 1380.5 \pm 614.6 . (Table 1)

Comparison of the characteristics of the categorical variables between both groups was done using Chi squares test. There were statistically significant differences between them regarding sex, Child-Pugh score, ascites, and PHG. Male predominance was noted in group II (OV group); 36 cases $(72 \%)$ vs. 23 cases $(46 \%)$ in group I (Non-OV group). Most patients in group I were Child A (90\%), while most patients in group II were Child B and $\mathrm{C}(60 \%)$. The percentage of ascites in the Non-OV group was $8 \%$, which is much lower than that of the OV group (50\%), and the percentage of PHG in the Non-OV group was $12 \%$, which is much lower than that of the OV group (70\%). (Table 2)

Comparison of the characteristics of the two groups regarding numerical variables was performed using the independent t-test. All variables showed statistically significant differences except age. Platelet count was lower in the OV group $(136.7 \pm 53.7)$ compared to the Non-OV group (195.2 \pm 49.8$)$. INR was higher in the OV group $(1.5 \pm 0.5)$ compared to the Non-OV group $(1.1 \pm 0.3)$. Spleen diameter was higher in the OV group (139.2 \pm 21.5$)$ compared to the Non-OV group (115.7 \pm 8.7$)$. PV diameter was higher in the OV group (13.1 \pm 1.8$)$ compared to the NonOV group (11.3 \pm 1.1$)$. GBWT was higher in the OV group (4.2 \pm 1.2$)$ compared to the NonOV group $(2.7 \pm 0.7)$. Platelet count to spleen diameter ratio was lower in the OV group (1056.1 \pm 548.6$)$ compared to the Non-OV group (1704.8 \pm 497.6$)$. Albumin level was lower in the OV group $(3.2 \pm 0.3)$ compared to the Non-OV group (3.6 \pm 0.3$)$. (Table 3)

Using multivariate analysis by logistical regression including age, sex, ascites, PHG, GBWT, spleen diameter, Portal Vein diameter, INR, platelet count, albumin, and platelet count to spleen diameter ratio, we found that GBWT, platelet count, platelet count to spleen diameter ratio and $\mathrm{PV}$ diameter are independent predictor factors of OV. (Table 4)

GBWT at a cut-off value $\geq 3.350$ had $68 \%$ sensitivity, $78 \%$ specificity, $75.6 \% \mathrm{PPV}$, and 
$70.9 \%$ NPV for detection of OV (Table 5), with $\mathrm{AUC}=0.828$ (Figure 2)

GBWT at cut-off level $\geq 3.950$ had $92 \%$ sensitivity, $95 \%$ specificity, $86.7 \% \mathrm{PPV}$, and 97.1\% NPV for detection of large-sized OV (Table 7), with AUC $=0.986$. (Figure 4)

Platelet count to spleen diameter ratio at cutoff level $\leq 1391.00$ showed $80 \%$ sensitivity, $70 \%$ specificity, $21.7 \%$ PPV, and $25.9 \%$ NPV for detection of OV (Table 6), with AUC= 0.826 (Figure 3), and at cut-off level $\leq 1175.50$, it had $96 \%$ sensitivity, $89 \%$ specificity, $98.5 \%$ PPV and $77.1 \%$ NPV for detection of large sized OV(Table 8), with $\mathrm{AUC}=0.984$. (Figure 5)

GBWT at a cut-off value $\geq 3.350$ was less sensitive and less specific than platelet count

\section{Table 1: Characteristics of participants}

\begin{tabular}{|c|c|c|c|}
\hline \multirow{2}{*}{\multicolumn{2}{|c|}{ Sex $\quad$ Male }} & \multirow{2}{*}{$\begin{array}{l}\text { Frequency } \\
59\end{array}$} & \multirow{2}{*}{$\begin{array}{l}\text { Percent } \\
59 \%\end{array}$} \\
\hline & & & \\
\hline & Female & 41 & $41 \%$ \\
\hline \multirow{3}{*}{$\begin{array}{l}\text { Child-Pugh } \\
\text { score }\end{array}$} & A & 65 & $65 \%$ \\
\hline & $\mathrm{B}$ & 21 & $21 \%$ \\
\hline & $\mathrm{C}$ & 14 & $14 \%$ \\
\hline \multirow[t]{2}{*}{ Ascites } & no & 71 & $71 \%$ \\
\hline & yes & 29 & $29 \%$ \\
\hline \multirow[t]{2}{*}{ PHG } & no & 59 & $59 \%$ \\
\hline & yes & 41 & $41 \%$ \\
\hline \multirow{3}{*}{ Groups } & Non-OV & 50 & $50 \%$ \\
\hline & OV & 50 & $50 \%$ \\
\hline & & Mean & SD \\
\hline \multicolumn{2}{|l|}{ Age (years) } & 56.1 & 8 \\
\hline \multicolumn{2}{|l|}{ Platelet count } & 165.9 & 59.3 \\
\hline \multicolumn{2}{|l|}{ INR } & 1.3 & 0.5 \\
\hline \multicolumn{2}{|c|}{ Albumin (g/dl) } & 3.4 & 0.3 \\
\hline \multicolumn{2}{|c|}{ Spleen diameter (mm) } & 127.5 & 20.1 \\
\hline \multicolumn{2}{|c|}{ PV diameter(mm) } & 12.2 & 1.7 \\
\hline \multicolumn{2}{|l|}{ GBWT(mm) } & 3.4 & 1.2 \\
\hline \multicolumn{2}{|c|}{ Platelet count to spleen diameter ratio } & 1380.5 & 614.6 \\
\hline
\end{tabular}

Table 2: Comparison of the characteristics (categorical variables)

\begin{tabular}{|c|c|c|c|c|}
\hline & & $\begin{array}{l}\text { Group I (Non- } \\
\text { OV) }\end{array}$ & Group II (OV) & p-value \\
\hline \multirow[t]{2}{*}{ Sex } & Male & $\begin{array}{l}23 \\
46.00 \%\end{array}$ & $\begin{array}{l}36 \\
72.00 \%\end{array}$ & \multirow[t]{2}{*}{0.008} \\
\hline & Female & $\begin{array}{l}27 \\
54.00 \%\end{array}$ & $\begin{array}{l}14 \\
28.00 \%\end{array}$ & \\
\hline Child-Pugh score & A & $\begin{array}{l}45 \\
90.00 \%\end{array}$ & $\begin{array}{l}20 \\
40.00 \%\end{array}$ & $<0.001$ \\
\hline
\end{tabular}
$\leq 1391.00$ for detection of OV, while GBWT at cut-off level $\geq 3.950$ was more specific and more sensitive than platelet count to spleen diameter ratio at the same (previously mentioned) cut-off level.

On studying the correlation between GBWT and PV diameter using Pearson correlation coefficient showed that there was a strong positive correlation ( $\mathrm{r}=0.0 .7932)$ and ( $\mathrm{r}=0.889$ ) in group I and II respectively ( Figure 6-7). Similarly, there was a strong positive correlation between GBWT and grade of OV $(\mathrm{r}=0.7856)(\mathrm{P}-$ Value is $<0.0001)$ (Figure 8) 


\begin{tabular}{|c|c|c|c|c|}
\hline & & $\begin{array}{l}\text { Group I (Non- } \\
\text { OV) }\end{array}$ & Group II (OV) & p-value \\
\hline \multirow{4}{*}{ Ascites } & B & $\begin{array}{l}3 \\
6.00 \%\end{array}$ & $\begin{array}{l}18 \\
36.00 \%\end{array}$ & \multirow{4}{*}{$<0.001$} \\
\hline & $\mathrm{C}$ & $\begin{array}{l}2 \\
4.00 \%\end{array}$ & $\begin{array}{l}12 \\
24.00 \%\end{array}$ & \\
\hline & No & $\begin{array}{l}46 \\
92.00 \%\end{array}$ & $\begin{array}{l}25 \\
50.00 \%\end{array}$ & \\
\hline & Yes & $\begin{array}{l}4 \\
8.00 \%\end{array}$ & $\begin{array}{l}25 \\
50.00 \%\end{array}$ & \\
\hline \multirow[t]{2}{*}{ PHG } & No & $\begin{array}{l}44 \\
88.00 \%\end{array}$ & $\begin{array}{l}15 \\
30.00 \%\end{array}$ & \multirow[t]{2}{*}{$<0.001$} \\
\hline & Yes & $\begin{array}{l}6 \\
12.00 \%\end{array}$ & $\begin{array}{l}35 \\
70.00 \%\end{array}$ & \\
\hline
\end{tabular}

Table 3: Comparison of the characteristics (numerical variables)

\begin{tabular}{|c|c|c|c|c|c|}
\hline & \multicolumn{2}{|c|}{$\begin{array}{l}\text { Group I (Non- } \\
\text { OV) }\end{array}$} & \multicolumn{2}{|c|}{ Group II (OV) } & \multirow[t]{2}{*}{ P-value } \\
\hline & Mean & SD & Mean & SD & \\
\hline Age (years) & 55.6 & 8.1 & 56.5 & 8.1 & 0.578 \\
\hline Platelet count & 195.2 & 49.8 & 136.7 & 53.7 & $<0.001$ \\
\hline INR & 1.1 & 0.3 & 1.5 & 0.5 & $<0.001$ \\
\hline Spleen diameter $(\mathrm{mm})$ & 115.7 & 8.7 & 139.2 & 21.5 & $<0.001$ \\
\hline PV diameter(mm) & 11.3 & 1.1 & 13.1 & 1.8 & $<0.001$ \\
\hline GBWT(mm) & 2.7 & 0.7 & 4.2 & 1.2 & $<0.001$ \\
\hline $\begin{array}{l}\text { Platelet count to spleen } \\
\text { diameter ratio }\end{array}$ & 1704.8 & 497.6 & 1056.1 & 548.6 & $<0.001$ \\
\hline Albumin $(\mathrm{g} / \mathrm{dl})$ & 3.6 & 0.3 & 3.2 & 0.3 & $<0.001$ \\
\hline
\end{tabular}

Table 4: Multiple logistic regression for the variables associated with the presence of $\mathrm{OV}$

\begin{tabular}{|c|c|c|c|c|c|}
\hline & \multirow{2}{*}{$\begin{array}{l}\text { Unadjusted } \\
\text { OR }\end{array}$} & \multirow{2}{*}{$\begin{array}{l}\text { Adjusted } \\
\text { OR }\end{array}$} & \multirow[t]{2}{*}{ P-value } & \multicolumn{2}{|c|}{ 95\% C.I. for OR } \\
\hline & & & & Lower & Upper \\
\hline Age & 1.01 & 0.94 & 0.178 & 0.85 & 1.03 \\
\hline Sex (male) & Ref & & & & \\
\hline Sex (female) & 0.33 & 0.34 & 0.168 & 0.07 & 1.58 \\
\hline Ascites (No) & Ref & & & & \\
\hline Ascites (Yes) & 11.50 & 0.05 & 0.125 & 0.00 & 2.36 \\
\hline Platelet count & 0.98 & 0.84 & 0.048 & 0.71 & 1.00 \\
\hline INR & 14.03 & 0.18 & 0.364 & 0.00 & 7.29 \\
\hline Spleen diameter & 1.10 & 1.41 & 0.008 & 1.09 & 1.81 \\
\hline PV diameter(mm) & 2.16 & 0.13 & 0.008 & 0.03 & 0.58 \\
\hline GBWT(mm) & 4.66 & 41.65 & 0.004 & 3.39 & 511.21 \\
\hline $\begin{array}{l}\text { Lower platelet count } \\
\text { to spleen diameter } \\
\text { ratio }\end{array}$ & 1.00 & 1.02 & 0.039 & 1.00 & 1.04 \\
\hline PHG(No) & Ref & & & & \\
\hline PHG(Yes) & 17.11 & 4.43 & 0.215 & 0.42 & 46.55 \\
\hline Albumin & 0.01 & 0.03 & 0.074 & 0.00 & 1.40 \\
\hline
\end{tabular}




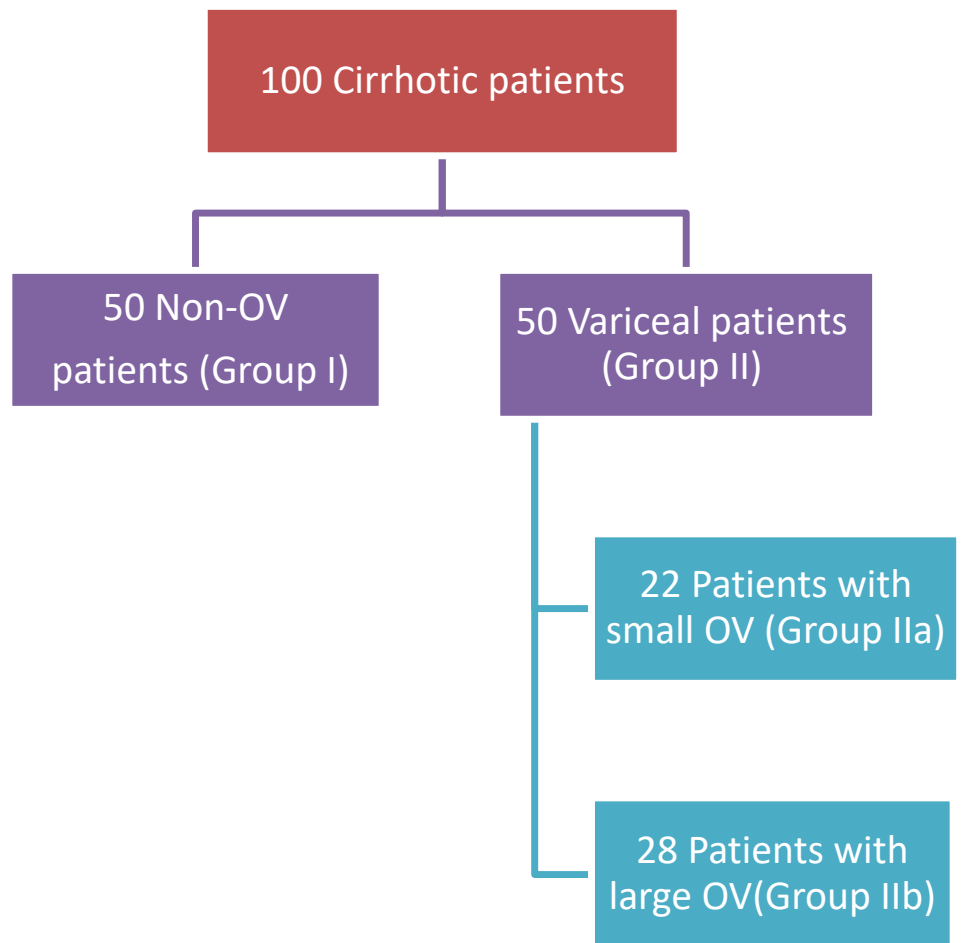

Figure 1: Patients were divided according to the results of the upper GI endoscopy into the shown groups.

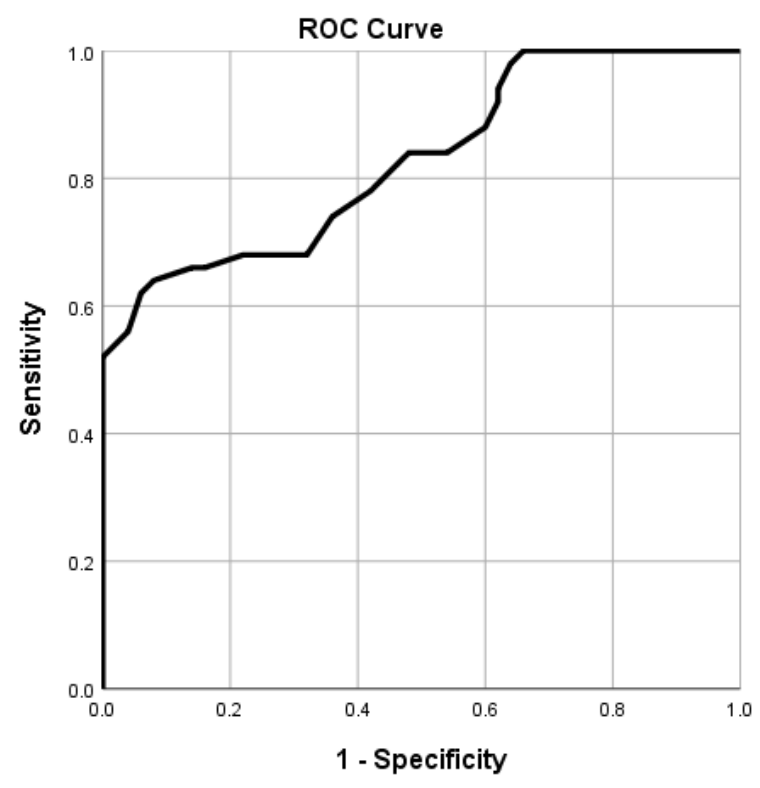

Diagonal segments are produced by ties.

Figure 2: $\mathrm{ROC}$ for $\mathrm{OV}$ using GBWT, $\mathrm{AUC}=0.828$ 


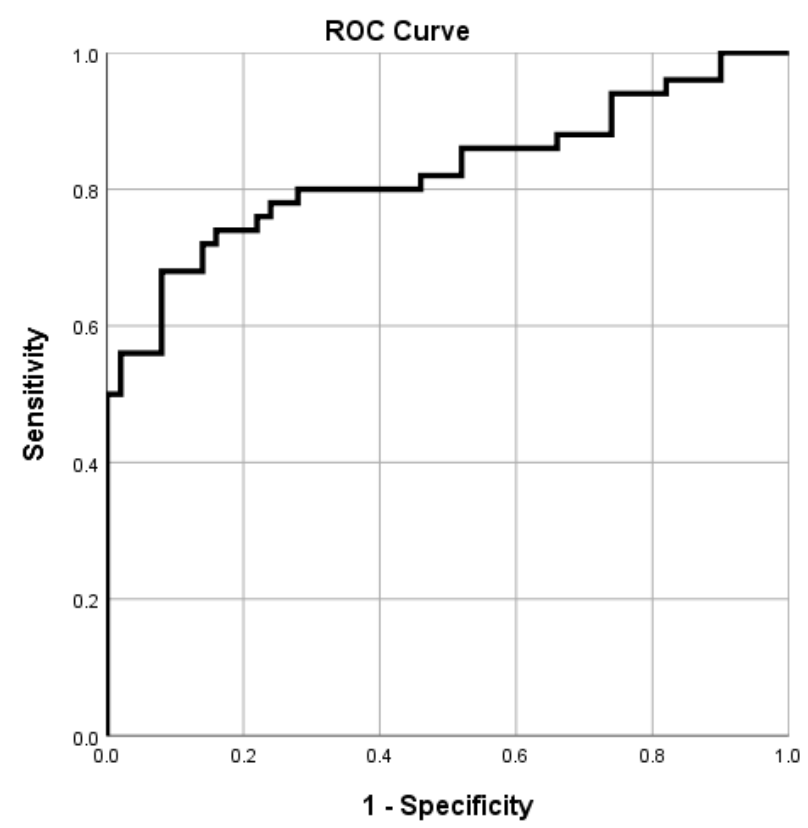

Figure 3: ROC for OV using platelet count to spleen diameter ratio, AUC 0.826

\section{DISCUSSION}

Oesophageal varices developed in about $40 \%$ of patients with liver cirrhosis [10]. O.V are the most critical portosystemic shunts that develop as a consequence of portal hypertension. Prophylactic band ligation and use nonselective beta-blockers may decrease the risk of variceal bleeding by $50 \%$ [11]. To avoid bleeding from OV, it is recommended to perform an upper GI endoscopy as soon as the patients are diagnosed as liver cirrhosis $[12,13]$. Endoscopic screening of all cirrhotic patients causes burden to patients and to endoscopic units as well as unnecessary endoscopic interventions [14].Thus, more accurate noninvasive parameters for $\mathrm{OV}$ prediction could reduce the need for upper GI endoscopies in variceal screening [15]. In the current study we based on the diagnostic utility of noninflammatory GBWT measured by ultrasound as a non-invasive predictor of $\mathrm{OV}$ in cirrhotic patients as regard their presence and their size. Because portal venous blood drainage of the gall bladder, we assumed that the GBWT may help in the prediction of the presence of portal hypertension and OV. As regard GBWT, the present study revealed a significant difference between the cirrhotic group with OV (group II) and that without OV (group I) (P <0.001). The mean GBWT in patients have liver cirrhosis with OV was $4.2 \mathrm{~mm}$ while it was $2.7 \mathrm{~mm}$ in those without OV. This result are comparable to the study done by Shamsi et al. [16] who stated that the mean GBWT of patients without OV $(2.7 \pm 0.1 \mathrm{~mm})$ was significantly less $(\mathrm{P}<0.01)$ than that of patients with $\mathrm{OV}(5.6 \pm 0.2 \mathrm{~mm})$. Formerly, it has been thought that GBWT in chronic liver disease has occurred secondary to hypoalbuminemia. It has been found that the stomach wall thickens in patients with congestive gastropathy[17] and it has been suggested that portal hypertension causing edema and congestion in the gallbladder wall may also induce congestive cholecystopahty in chronic liver disease patients in the absence of hypoalbuminemia or ascites. [18].

In the current study, GBWT at cut-off value $3.35 \mathrm{~mm}$ had a sensitivity of $68 \%$, a specificity of $78 \%$, PPV of $75.6 \%$, NPV of $70.9 \%$, and ROC analysis calculated AUC of 0.828 for detection of $\mathrm{OV}$ and at cutoff value $3.95 \mathrm{~mm}$, it had $92 \%$ sensitivity, $95 \%$ specificity, PPV of $86.7 \%$, NPV of $97.1 \%$ and ROC analysis calculated AUC of 0.986 in detecting large-sized OV in cirrhotic patients. Alcantara earlier published a cut-off value of $4.35 \mathrm{~mm}$ for a thickened gall bladder wall and found a sensitivity of $60 \%$ and a specificity of $90 \%$ as regard the presence of OV in pediatric patients [19]. The sensitivity was comparable 
to our study, although a higher value was used as a cut-off. Other explanations for this difference might be the different patient cohorts as Alcantara based his study on data from children with different causes of cirrhosis such as biliary atresia and autoimmune hepatitis [19]. A small Chinese study had reported a correlation between portal hypertension and GBWT, supporting the hypothesis that GBWT would also predict the presence of OV [20].

The current study detected a significant decrease in the mean values of platelet count/ splenic diameter ratio in cirrhotic patients with varices in contrast to those without varices $(\mathrm{P}<0.001)$. additionally, our study found that platelet count/ splenic diameter ratio at cutoff value 1391 had sensitivity $80 \%$, specificity $72 \%$, PPV $21.7 \%$, and NPV $25.9 \%$ for detection of OV and at cutoff $1175.5 \mathrm{had}$ sensitivity $96 \%$, specificity $89 \%$, PPV $98.5 \%$ and NPV $77.1 \%$ for detection of large varices. This came with Abo-Alsoud et al. [21] who reported; a significant decrease in the mean values of platelet count/ spleen diameter ratio in cirrhotic patients with varices in comparison to other patients without varices, and that the best cut-off value for detection of O.V was 638.9 with sensitivity $100 \%$, specificity $97.5 \%$, PPV $95.2 \%$, and NPV $100 \%$. In agreement with our results, Esmat et al. [22] showed that the platelet/spleen diameter at a cut-off point of 1326.6 can predict OV with $96.3 \%$ sensitivity, $83.3 \%$ specificity, 96.3\% PPV, and $83.3 \%$ NPV. In comparison to the current results, Qamar et al. [23] and Hassan,et al. [24] found that platelets/splenic longitudinal diameter (PLT/SLD) ratio did not revealed a significant difference in patients with and without OV, suggesting that these method cannot be used in the prediction of the presence of varices. This conflict may be attributed to differences in the severity of liver disease in our patients as $60 \%$ of group II cases in our study were Child B \&C and $90 \%$ of group I were Child A, despite the previous studies included patients with Child "A" and early "B" liver cirrhosis who had less impairment of platelet. In the present study and in accordance to the multivariate logistic regression analysis for predicting of $\mathrm{OV}$, we revealed that GBWT, platelet count, PV diameter, spleen diameter, and platelet/spleen diameter ratio were independent predictors of OV. This result was comparable to Tsaknakis et al. [25], who showed that GBWT, ascites, platelet count, and spleen diameter were independent predictors of $\mathrm{OV}$.

The limitations of the current study were the small number of participants and unidentified number of ultrasonography operators. On the other hand, some points in the methodology overcome that limitation . First, both ultrasonography and endoscopy were performed on the same day, limiting overtime changes in endoscopy and personnel changes in the sonographic findings. Second, we studied patients in a cross-sectional fashion and sometimes prospectively; consequently, we did not miss many of the important clinical and laboratory parameters.

\section{CONCLUSION}

GBWT might be used as a non-invasive method in the prediction of the presence of $\mathrm{OV}$, as this correlated with the size of OV.

Data Availability: The datasets used and analyzed during the current study are available from the corresponding author on reasonable request.

Funding: Not Available.

Conflicts of interest: Not Available.

Ethical Considerations: Approved; all participants have provided written consent.

\section{REFERENCES}

1. Asrani SK, Devarbhavi H, Eaton J, Kamath PS. Burden of liver diseases in the world. J Hepatol 2019; 70:151-71.

2. Nusrat S, Khan MS, Fazili J, Madhoun MF. Cirrhosis and its complications: evidence based treatment. World J Gastroenterol WJG 2014; 20:5442.

3. De franchis R. Revising consensus in portal hypertension : Report of the Baveno V consensus workshop on definitions, methodology, and therapy in portal hypertension. J Hepatol 2010; 53:762-68.

4. Merli M, Nicolini G, Angeloni S, Rinaldi V, De Santis A, Merkel C, et al. Incidence and natural history of small esophageal varices in cirrhotic patients. J Hepatol. 2003; 38:266-72.

5. Hsieh Y-C, Lee K-C, Chen P-H, Su C-W, Hou M$\mathrm{C}$, Lin H-C. Acute kidney injury predicts mortality in cirrhotic patients with gastric variceal bleeding. J Gastroenterol Hepatol. 2017; 32:1859- 
66.

6. de Franchis R, Primignani M. Natural history of portal hypertension in patients with cirrhosis. Clin Liver Dis. 2001;5: 645-63.

7. Garcia-Pegan, Garcia-sancho. Functional aspects on pathophysiology in portal hypertension in liver cirrhosis. J Hepatol 2012; 57(2),458-61.

8. Berzigotti A1, Gilabert R, Abraldes JG, Nicolau C, Bru C, Bosch J., et al. Noninvasive prediction of clinically significant portal hypertension and oesophageal varices in patients with compensated liver cirrhosis. Am.J. Gastroenterol 2008; 103(5),1159-67.

9. Way LW, Pellegrini CA, editors. Surgery of the gallbladder and bile ducts. Philadelphia: Saunders; 1987.

10. Pagliaro L, D'Amico G, Pasta L, et al. Portal hypertension in cirrhosis: natural history. In: Bosch J, Groszmann RJ, editors. Portal Hypertension Pathophysiology and Treatment. Oxford: Blackwell Science, 1992: 72-92.

11. Giannelli V, Lattanzi B, Thalheimer U, Merli, M. Beta-blockers in liver cirrhosis. Ann. Gastroenterol 2014; 27 (1): 20-26.

12. Denzer U, Beilenhoff U, Eickhoff A, Faiss S, Hüttl $\mathrm{P}$, In der Smitten $\mathrm{S}$, et al. S2k guideline: quality requirements for gastrointestinal endoscopy, AWMF registry no. 021-022. Z Gastroenterol. 2015; 53:E1-227.

13. Sarin SK, Lahoti D, Saxena SP, Murthy NS, Makwana UK. Prevalence, classification and natural history of gastric varices: a long-term follow-up study in 568 portal hypertension patients. Hepatol Baltim Md. 1992; 16:1343-9.

14. De Franchis R. Noninvasive diagnosis of esophageal varices: is it feasible? Am. J. Gastroenterol 2006; 101: 25202.

15. Wang L, Hu J, Dong S, Jian YC, Hu L, Yang G, et al. Noninvasive prediction of large esophageal varices in liver cirrhosis patients. Clin Invest Med 2014; 37 (1): 38-46.

16. Shamsi A, Arif A , Kanta D , Sharmistha D , Akhtar U, Mohsin K, et al. Thickening of gallbladder wall in chronic liver disease. Coll. J. 2012; 6(1): 18-20.

17. Saverymuttu SH, Corbishley CM, Maxwell JD,
Joseph AE. Thickened stomach- an ultrasound sign of portal hypertension. Clin Radiol 1990; 41(1): 17-8.

18. Gabata T, Matsui O, Kadoya M, et al. Gallbladder varices: demonstration of direct communication to intrahepatic portal veins by color doppler sonography and CT during arterial portography. Abdom Imaging 1997; 22(1): 82-84.

19. de Alcantara RV, Yamada RM, Cardoso SR, de Fátima M, Servidoni CP, Hessel G. Ultrasonographic predictors of esophageal varices. J Pediatr Gastroenterol Nutr. 2013;57:700-3.

20. Li C, Yang Z, Ma E, Liu Y. Analysis of the correlation between the degree of GBWT and hemodynamic changes of portal vein system. Sheng Wu Yi Xue Gong Cheng Xue Za Zhi J Biomed Eng Shengwu Yixue Gongchengxue Zazhi. 2010; 27:583-5. 625.

21. Abo-Alsoud A.A; Badawy A.M; Sonbol A.A; Ayad M.E. Study of the Relationship between Blood Ammonia Level and Esophageal Varices in Patients with Liver Cirrhosis Afro-Egypt J Infect Endem Dis 2015; 5(2): 78-85.

22. Esmat S, Omarn D, Rashid L. Can we consider the right hepatic lobe size/albumin ratio a noninvasive predictor of oesophageal varices in hepatitis C virus-related liver cirrhotic Egyptian patients? Eur. J. Intern. Med. 2012; 23: 267-72.

23. Qamar AA, Grace ND, Groszmann RJ, GarciaTsao G, Bosch J, Burroughs AK., et al. Platelet count is not a predictor of the presence or development of Gastroesophageal varices in cirrhosis. Hepatology 2000; 47: 153-159.

24. Hassan EA; Abd El-rehim AS ; Sayed ZA; Kholef EF; Hareedy MA ; Abd EL-aaL RF. NonInvasive Parameters of Oesophageal Varices Diagnosis: Which Sensitive and Applicable; A Pilot Study. J Liver 2015; 4:3.

25. Birgit TS, Rawan M, Ahmad AM, Golo P, Volker EL, Albrecht $\mathrm{N}$, et al, Gall bladder wall thickening as noninvasive screening parameter for esophageal varices - a comparative endoscopic sonographic study. BMC Gastroenterology 2018; 18 (1): 123 .

\section{To Cite}

Afifi, M., Rizk, M., Hussein, A. Gall bladder Wall Thickness as Non-invasive Predictor of Oesophageal Varices in Cirrhotic Patients. Zagazig University Medical Journal, 2022; (54-62): -. doi: 10.21608/zumj.2021.77155.2239 